\title{
Design of 3D Animation Special Effects in Animation 3D Modeling Teaching Based on QFD Theory
}

\author{
https://doi.org/10.3991/ijet.v12i07.7218 \\ Qiong Wang \\ University of Science and Technology Liaoning, Anshan, China \\ $\operatorname{lnkjdx} 0 \quad 0 @ 163 . \mathrm{com}$
}

\begin{abstract}
A multimedia teaching device based on synchronous text teaching content display was designed by utilizing multimedia and animation technology. The device can make relevant text appear synchronously while the teaching video is played. It can achieve perfect combination of video and text, reduce learning load and improve learning efficiency. To estimate this new teaching device, we chose the students as the objects of study before and after using the device, and combined QFD theory for quantitative evaluation. Finally, such conclusion was drawn that this teaching device indeed has an ideal teaching effect.
\end{abstract}

Keywords-Synchronous text, multimedia teaching, 3D animation, Quality Function Deployment (QFD) theory

\section{Introduction}

In traditional teaching process, we often adopt texts, simple graphs and material objects as teaching aid means to enhance teaching effect. But, complex things, substances, principles, concepts and conceptions can only be taught in the form of text and imagination and finally form very abstract concepts. Comprehension requires rich spatial imagination ability. Thus, it is especially difficult to impart such knowledge. Because of rapid development of multimedia technology, we can now use pictures, projection and 3D animation to enhance teaching effect. 3D animation [1] is a stereoscopic, all-round and dynamic teaching mode. With it, we can establish the dynamic model closer to the truth and make abstract and dull knowledge become concrete and interesting. Hence, it is widely applied.

With rapid development of computer technology, we can carry out geometric modeling design of objects in the virtual 3D world, i.e. 3D modeling. 3D modeling is the foundation of 3D animation [2]. During 3D animation production, we first simulate a virtual 3D world with 3D animation software, and then give 3D model different materials to enhance authenticity. Next, we design the operation track of 3D model, simulate vidicon records, apply lamplight, and finally output the frames to generate 3D animation. 3D animation can visually present the teaching content in a threedimensional and dynamic way. Plus material giving and light simulation, 3D animation has very strong sense of reality and breaks imagination limitation. Besides, it 
fully invokes audio-video information channel, effectively enhances teaching effect and reduces cognition load.

\section{Research Progress Review}

3D animation technology is applied in teaching multiple disciplines. For example, Chen and Huang applied 3D animation in hand painting course. This system fully utilized computer graph, image processing technology and network resources, and a new method to rapidly interact 3D animation technology was proposed. The whole system was divided into two subsystems: director script generation subsystem and 3D animation generation subsystem. A multi-source visual media material library based on Internet was built by using such key techniques as high-level semantic annotation, image and 3D model retrieval, image segmentation, image seamless fusion, 3D rendering. Meanwhile, a complete set of rapid animation creation system was implemented. Actual user experience test shows that, this system is convenient to operate and can effectively improve animation production efficiency, with good visual expression effect [3]. Abid et al. tried to apply 3D in anatomy teaching. This study aimed to compare the teaching effect between 3D teaching and traditional chalk teaching in the aspect of students' memorization about peritoneal embryogenesis. The results verify that $3 \mathrm{D}$ technology shows a better teaching effect than traditional chalk technique for peritoneal embryogenesis teaching in terms of short-term memorization and particularly for the assimilation of dynamic phenomena [4].

The extensive application of $3 \mathrm{D}$ animation leads to different animation output ways. The output ways can be classified into the following types according to facility difference [5]: (1) single computer displayer. But, the computer displayer is usually small, so it is not suitable for classroom teaching. (2) E-classroom. E-classroom perfectly combines network and multimedia technology, and it can achieve animation storage and playing, voice talkback, asking for help, group teaching, assignment distribution and submission etc. (3) Projection. The projection screen is large and suitable for classroom teaching. In traditional 3D animation, the text part and dynamic pictures are synthesized to different processes in the same animation. When the animation is played, texts and dynamic pictures are separated. Or, the text part and dynamic pictures are stored into two animation files, and the playing speed is controlled to be consistent so as to ensure content consistency. Brown once applied 3D in astronomy teaching, and demonstrated the process in which the common table top activities based on the Orion constellation missed out on this chance. Through transformation into a walk-through Orion installation including the position of our Solar system, students could be fully absorbed in model and experience parallax. In the installation process, it could make participants explore many other aspects of astronomy such as sky culture, stellar evolution, and stellar timescales so as to establish an innovative learning and teaching environment [6].

At present, animation 3D modeling course is mainly taught with 3D software in universities. Since the teaching method is based on software application, the teachers of computer major are required for teaching design. Professional theory course setup 
of animation modeling is short or rarely involved [7]. Secondly, due to strong functions, complex interfaces, rich contents and numerous modules of all kinds of 3D animation software, the class hour of such course is generally long. However, students just learn how to operate a kind of animation software, though they spend much time. More importantly, various universities have different application software for animation major teaching, which results in the shortage of uniform and standard teaching materials. The teaching contents of 3D animation mostly come from all kinds of books in the society or the teaching material prepared by teachers according to their own knowledge. All these factors lead to the deficiency of 3D animation teaching development.

In this study, we adopted a multimedia teaching device based on synchronous text teaching content. This device is also based on the development of internet and multimedia technology. The device is equipped with text storage device, and teaching texts in each stage correspond to explanation teaching video and animation teaching video respectively. The multimedia teaching device also includes note generation module which can form user's notes through module input in multimedia teaching. Thus, when the video and animation are played, the display device immediately changes over to the paragraph mark corresponding to the video so that the text and teaching content achieve synchronization. This promotes students' learning efficiency. User note setting allows users to record their feeling, difficult points and outlines when receiving knowledge. The device gives students a platform for organizing and sorting knowledge synchronously and enhances their autonomous learning ability. Moreover, QFD theory is applied for quantitative evaluation of the quality of this multimedia teaching device. In this way, good reference and experience are provided for us in future animation major teaching.

\section{$3 \quad$ Model Analysis}

The degree of education meeting social needs is the minimum standard for evaluating the quality of education. To evaluate the feasibility of this teaching device and its teaching quality, QFD theory [8] was chosen to evaluate it in this study. QFD was proposed in 1960s. This theory aims at customer demand and transforms customer value demand into product and service characteristics. The education industry provides the institutions for talent training. Hence, QFD has strong applicability for education industry.

QFD evaluation system is implemented through a series of charts, graphs and matrixes. These matrixes, charts and graphs are piled up to form the shape of a house, so it is also called "the house of quality" (HOQ) [9]. HOQ is the core of QFD evaluation process. The HOQ model can be established by taking course design for example according to the structure and composition of product design HOQ. The 7 components are shown as follows: 


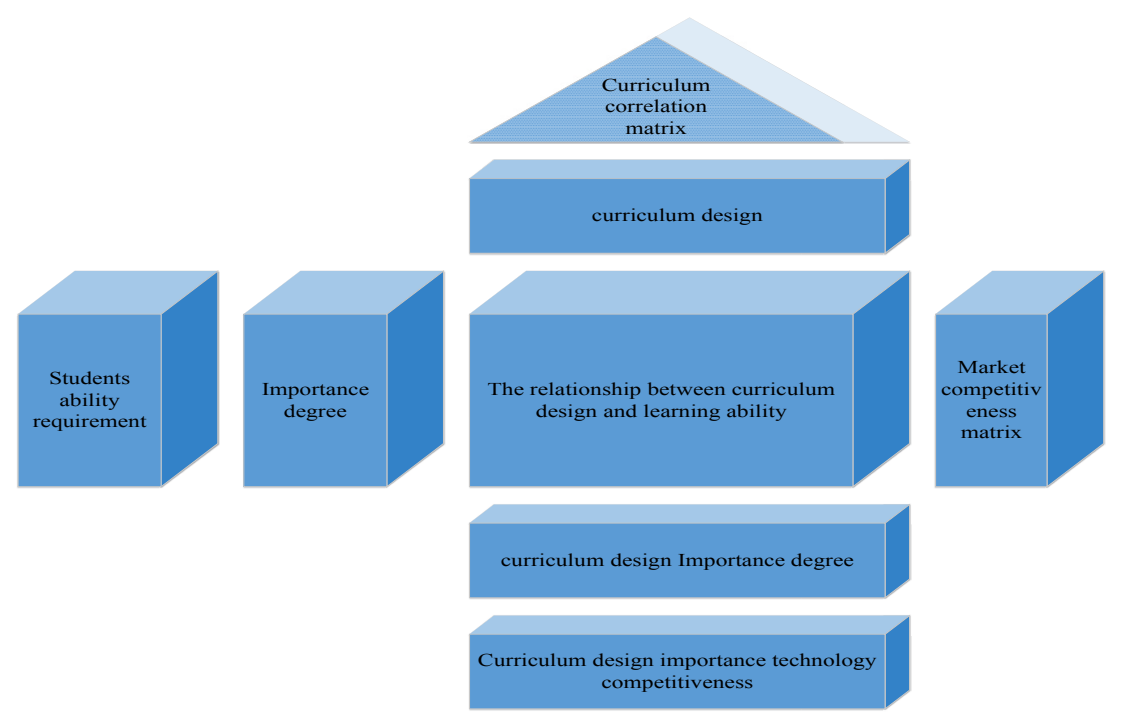

Fig. 1. HOQ model for teaching

In HOQ, students' ability demands can start from market survey, course objective and knowledge application degree. The students' ability demands gained are supplemented, concluded and organized. Besides, according to content similarity and inclusion relations, the demands are divided into different levels. Then, each level is quantified in accordance with the importance of each demand. The importance of students' ability demands is expressed with ki ( $\mathrm{i}=1,2, \cdots, \mathrm{m})$. If the importance of the demand is greater, the figure is larger. The relation between technical demand $\mathrm{j}$ of course design \& students' ability demands and course design is expressed with rij= $(i=1,2, \cdots, m ; j=1,2, \cdots, n)$. The relations between several demands \& students' ability demands and course design consist of the matrix of relation. The relation degree value is generally 1,3 and 9. The numerical value represents the relation intensity. The matrix value is the importance of course design.

$$
h_{i}=\sum_{i=1}^{m} k_{i} r i_{j}
$$

As for market competitiveness evaluation, the competitiveness $\mathrm{Mi}$ is divided into $\mathrm{i}$ grades for importance quantification according to the value of $\mathrm{Mi}$. the larger figure presents stronger. The matrix which is composed of students' ability demands and the importance represents market competitiveness, called market competitiveness index M. market competitiveness

$$
M=\frac{\sum_{i=1}^{m} k_{i} M_{i}}{5 \sum_{i=1}^{m} k_{i}}
$$


For technical competitiveness matrix, technical level includes $\mathrm{j}$ factors such as teaching team, teaching equipment and teaching process. The importance of each factor before and after the improvement is quantified with $1,2,3, \ldots, \mathrm{m}$. The larger figure means stronger technical competitiveness $\mathrm{Tj}$. Then, technical competitiveness matrix before and after the improvement is gained. The following calculation is conducted between technical competitiveness matrix and course design importance. The calculation result finally represents technical competitiveness, called technical competitiveness index $\mathrm{T}$.

$$
T=\frac{\sum_{j=1}^{m} h_{j} T_{j}}{5 \sum_{j=1}^{m} h_{j}}
$$

\section{$4 \quad$ Multimedia Teaching Device}

\subsection{Structure and function of multimedia teaching device}

This invention provides a multimedia teaching device based on synchronous text teaching content display, including user terminal, CPU, video database, animation database, text storage device, display device, speed regulation module, and paragraph selection module. Figure 2 shows the structure of this teaching device.

The user terminal is PC or palmtop which is equipped with multimedia teaching module. CPU, input module, network module, display device and note generation module are set up in the user terminal. The video database, animation database and text storage device are installed at the user terminal. The video database is used to store teaching explanation videos. The animation database is used to store animation teaching videos. Both databases are set up in the same storage device at the user terminal. Explanation videos and animation videos are marked as multiple paragraphs for the sake of continuous or segmented playing. Multimedia teaching module can also invoke the data in video database and animation database. The text storage device is used to store teaching texts, and each section of teaching text corresponds to corresponding paragraphs of explanation videos and animation videos. It is worth mentioning that the teaching text can include graphs and tables.

The display device is liquid crystal display panel or E-ink screen. It is used to display the teaching content. The speed regulation module and paragraph selection module are set up in the multimedia teaching module. They are used to regulate the speed of teaching explanation video and animation teaching video and video playing paragraph selection, respectively. Users may choose the paragraphs that they are interested in or the paragraphs that are difficult to understand through regulating the playing speed so as to increase or decrease learning difficulty and enhance learning efficiency. As shown in Fig.2, assignment generation module is also set up in the multimedia teaching module. The contents inputted in the input module immediately generate assignment files, and the assignment files are transmitted to the remote server through 


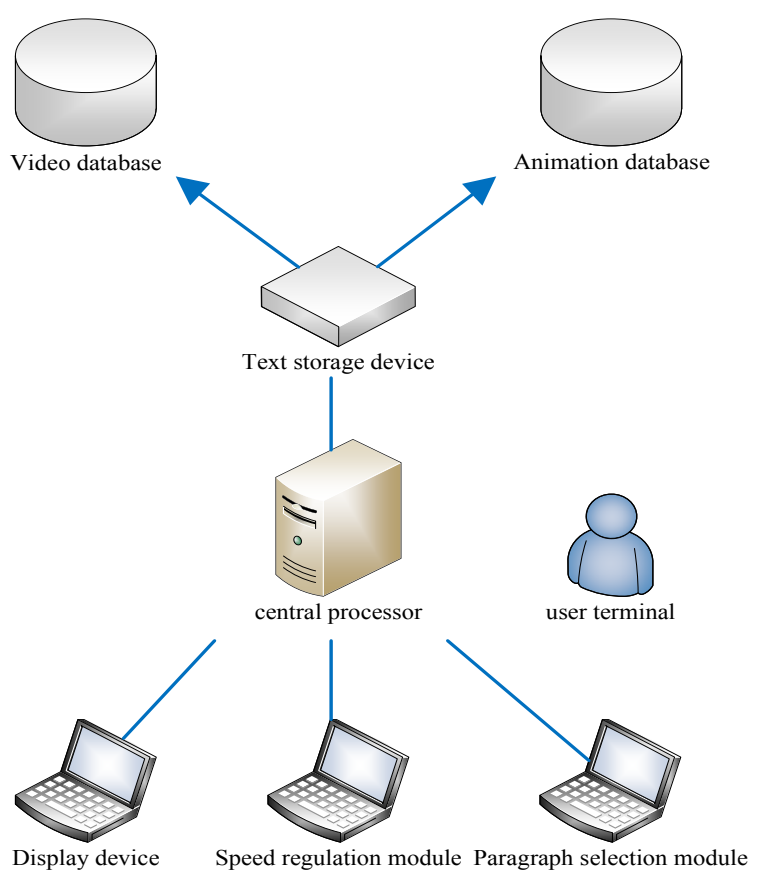

Fig. 2. Structure diagram of video module

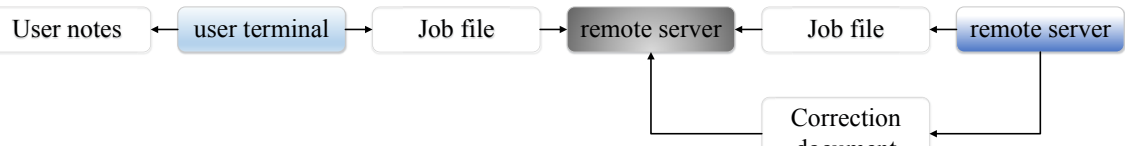

Fig. 3. Teaching interaction and note generation module

network module. The network module, assignment correction module and feedback module are installed in the teacher terminal, and they are used to generate correction file and send feed command to the remote server, respectively. After the remote serve receives the feedback command, it will inform the user to receive the correction file. Through the input module, users can form their own notes in the multimedia teaching module. In this way, users' teaching contents are closer to their learning situation, and this can reduce users' learning load.

In the video playing process, CPU detects corresponding text information with paragraph marks. The information not just includes segmentation reminding, but also includes paragraph number. Hence, the marked text and corresponding teaching text paragraph can correspond to each other accurately. Besides, the teaching text paragraph is displayed on the display device to achieve synchronized playing of video and text. This teaching device connects student terminal and teacher terminal through the remote server, and can achieve teaching and learning interaction. The assignment distribution and submission module makes teachers able to accurately judge students' learning effects. 


\subsection{Service terminal design for multimedia teaching device}

For the multimedia teaching device based on synchronous text teaching content display, there are mainly two kinds of service terminals according to the different main menus. The detailed use process is as follows:

1. The system restricts user right. Users need to input the correct account name and password to log in the system and enter the main menu of user system function.

2. The main menu of teacher terminal includes video, animation, network, assignment correction and feedback, as shown in Fig.3. After entering the main menu of teacher terminal, the teacher may choose the specific work module through clicking different opinions. If it is necessary to quit, the teacher may directly click the quit button.

3. The main menu of student terminal includes video, animation, network and assignment generation. The specific video and animation playing menu contains paragraph setting, paragraph selection, speed regulation and video playing. Here, we take the opening page of specific video (3D animation production course for organic chemistry) for example to show the selection module. The video may be set through choosing different options, or the playing button is clicked to play the video. If the learning ends, users may press the return button to choose other videos or directly quit the system.

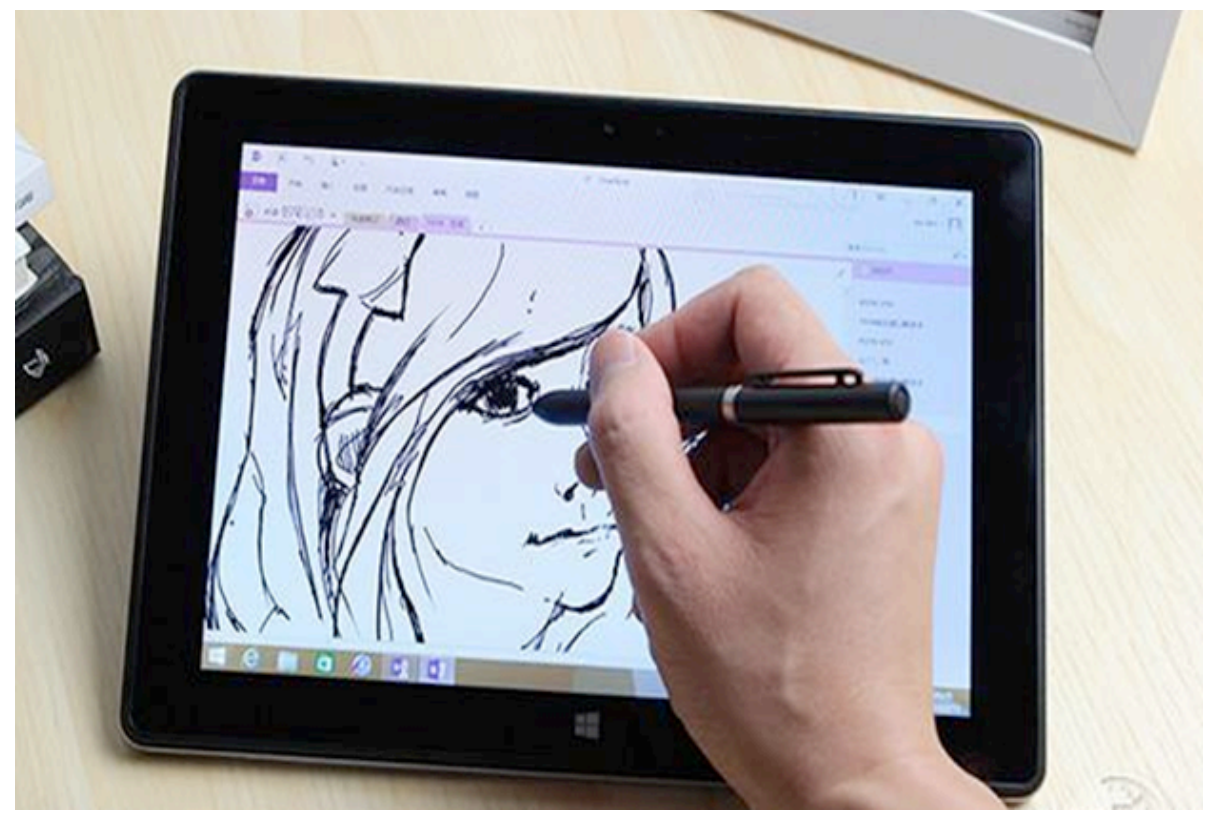

Fig. 4. Application of $3 \mathrm{D}$ animation effects in animation solid modeling teaching 


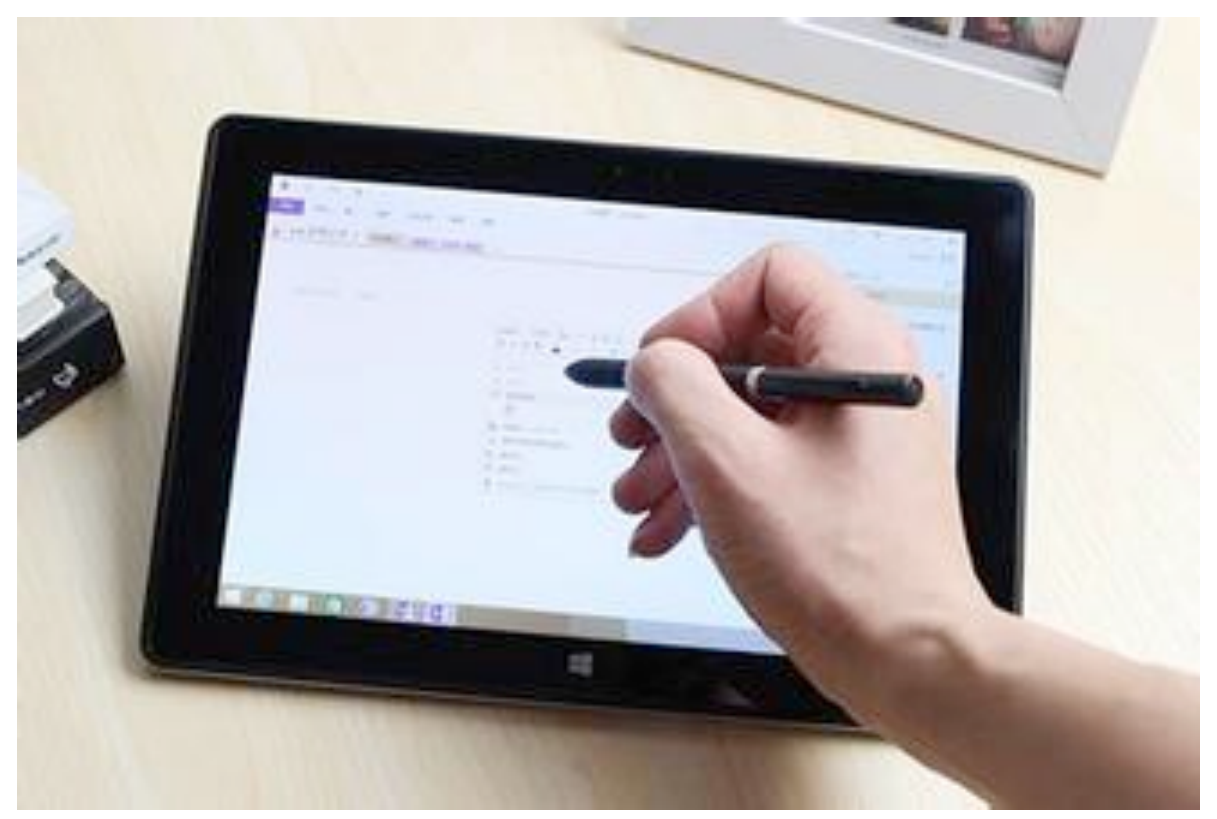

Fig. 5. The display of learning process with $3 \mathrm{D}$ animation effects

\subsection{Experiment design and data analysis}

The HOQ can not just improve products and services according to customer demand, but also evaluate product competitiveness in accordance with customer demand and different technical methods. In organic chemistry teaching, many compounds with complex molecular structure and complicated chemical reactions involve steric hindrance and reaction mechanism. Traditional picture or molecular formula teaching is not visual, and students are difficult to understand. Thus, to evaluate the teaching effect of multimedia teaching device system based on synchronous text teaching content display, animation modeling course of 120 animation majors in Grade 2012 and Grade 2013 respectively was chosen as the object of study. Traditional teaching method was applied for the students in Grade 2012, while this teaching device was used for the students in Grade 2013.

We adopted questionnaire method to investigate and interview students and teachers. The students' ability demands were divided into knowledge mastery degree, academic record, learning interest and learning ability according to the contents. Then, they were quantified according to the importance of each demand, and expressed with $1,2,3$, and 4 . The satisfaction degree value of students' ability demands before and after the improvement was divided with 1, 2, 3, 4 and 5. 5 represents "very satisfied", and 1 represents "very dissatisfied". For market competitiveness evaluation, we quantified the importance through dividing pre-use and post-use into Level 1 and Level 2. Technical level includes four factors, i.e. teaching team, teaching equipment, teaching plan and interaction between the teacher and students. The importance of each factor 
was quantified with 1, 2, 3 and 4, and the level of each factor before and after the use was quantified with 1, 2, 3, 4 and 5. 1 means "poor" and 5 means "good".

Through statistical survey, we gained the satisfaction degree of students' ability demands. The mean values are shown in the following figure.

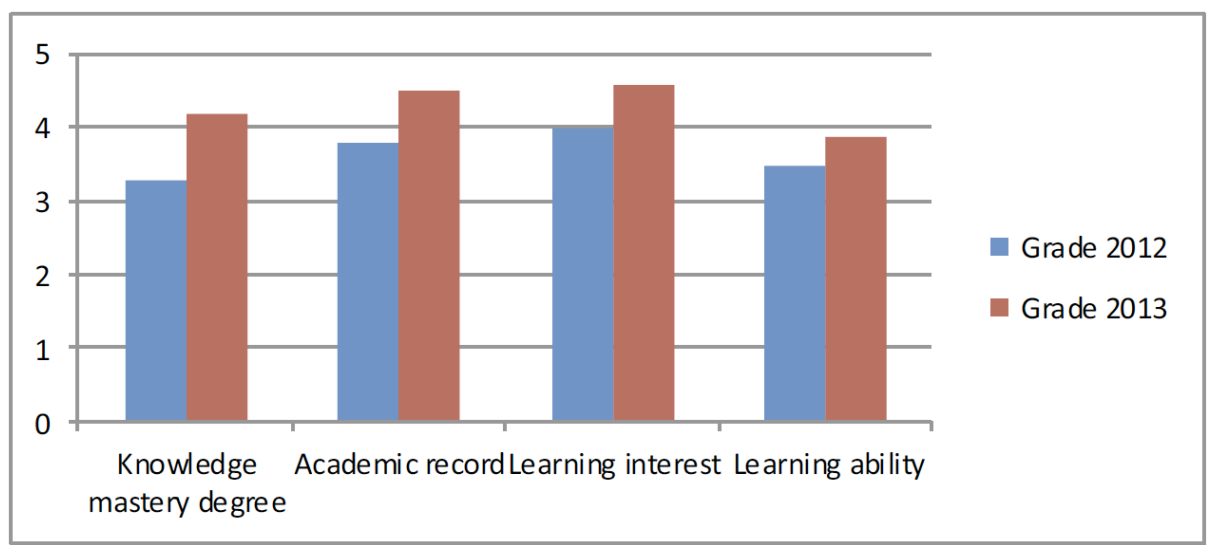

Fig. 6. Mean satisfaction degree of students' four ability demands

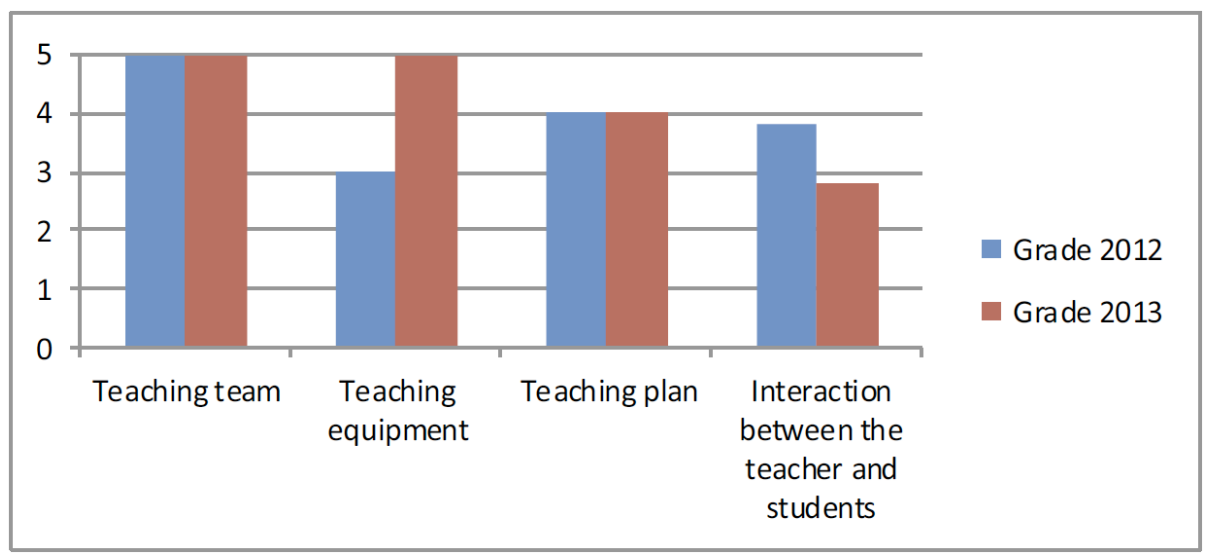

Fig. 7. Mean level value of four technical factors

According to Fig.6, knowledge mastery degree of sophomores in Grade 2012 is 3.3, while satisfaction degree of this ability demand of undergraduates in Grade 2013 is 4.2. Academic record satisfaction degree of students in Grade 2012 is 3.8, while the figure for students in Grade 2013 is 4.5. Satisfaction degree of learning interest demand for students in Grade 2012 is 4, while the figure for students in Grade 2013 is as high as 4.6. Satisfaction degree of learning ability demand for students in Grade 2012 is 3.5, while the figure for students in Grade 2013 is 3.9. It thus can be seen that the multimedia teaching device system based on synchronous text teaching content display can indeed improve students' learning efficiency and cultivate their learning 
interest. According to Fig.7, with the same teaching team and teaching plan, the improvement of teaching equipment can enhance the interaction between the teacher and students. Market competitiveness indexes before the after the use of the equipment gained in accordance with QFD are 0.62 and 0.82 respectively. Technical competitiveness indexes before the after the use of the equipment are 0.64 and 0.71 respectively. Thus, the multimedia teaching device system based on synchronous text teaching content display indeed greatly promotes students' learning.

\section{Conclusions}

A multimedia teaching device system based on synchronous text teaching content display was introduced in this paper. The main breakthroughs of this device lie in synchronous text and video teaching content. Meanwhile, note generation, paragraph design by users and teacher-student interaction are designed in this device. The teaching device can significantly boost students' learning effect and improve learning behaviors. Firstly, multimedia teaching course as an important resource of network remote teaching provides rich learning materials for learners. Secondly, QFD theory starts from teaching quality improvement, can understand students' evaluation and expectation for each teaching link and can recognize teaching quality improvement demand. In this way, teaching quality can really be improved. However in practice, teachers should rationally utilize new multimedia reaching devices and should not excessively depend on such platform. They need to adopt rational teaching methods to enlighten students, and require students to combine practice, think and practice more so as to cultivate their innovation consciousness and practical operation ability.

\section{References}

[1] Scherzer J, Buchanan M F, Moore J N, et al. Teaching veterinary obstetrics using threedimensional animation technology.[J]. Journal of Veterinary Medical Education, 2010, 37(3):299-303. https://doi.org/10.3138/jvme.37.3.299

[2] Makino H, Kobayashi E, Shiotani S, et al. Research on Construction of Visual Evaluation System for Safety Ship Navigation using Three-dimensional Animation[J]. Navigation, 2010:57-61.

[3] Chenyi N I, Huang D, Ding Y. Research on Rapid Interactive Three-dimensional Animation Creation System[J]. Video Engineering, 2014, 16(13):6050-6059.

[4] Abid B, Hentati N, Chevallier J M, et al. Traditional versus three-dimensional teaching of peritoneal embryogenesis: a comparative prospective study[J]. Surgical and Radiologic Anatomy, 2010, 32(7):647-652. https://doi.org/10.1007/s00276-010-0653-1

[5] Kuratate T. Statistical analysis and synthesis of 3D faces for auditory-visual speech animation[J]. Proceedings of Avsp', 2017:131--136.

[6] Brown D. The Orion Constellation as an Installation: An Innovative Three-Dimensional Teaching and Learning Environment[J]. Physics Teacher, 2011, 51(3):160-162. https://doi.org/10.1119/1.4792013

[7] Pęszor D, Polański A, Wojciechowski K. Preprocessing of 3D scanned images for facial animation on the basis of realistic acquisition[J]. 2015, 1648(1):950-953. 
Paper-Design of 3D Animation Special Effects in Animation 3D Modeling Teaching Based on QFD...

[8] Yang C H, Wei J, Xie Z, et al. Research on evaluation method of maintainability design based on QFD and D-S theory[J]. Journal of Engineering Design, 2009, 16(2):93-97.

[9] Liu J L, Zeng F M, Hao T U. Application of the QFD and TRIZ integrated theory on the conceptual design of marine power plant[J]. Journal of Dalian Maritime University, 2013, 39(4):86-90.

\section{Author}

Qiong Wang is a lecturer in the University of Science and Technology Liaoning, Anshan 114051, China (lnkjdx_0_0@163.com).

Article submitted 05 April 2017. Published as resubmitted by the authors 09 June 2017. 